FEDERAL

RESERVE

BANK of

RESEARCH DIVISION

Working Paper Series

\title{
On the substitutability between foreign aid and international credit
}

\author{
Subhayu Bandyopadhyay, \\ Sajal Lahiri \\ and \\ Javed Younas
}

\author{
Working Paper 2012-043A \\ https://doi.org/10.20955/wp.2012.043
}

October 2012

\author{
FEDERAL RESERVE BANK OF ST. LOUIS \\ Research Division \\ P.O. Box 442 \\ St. Louis, MO 63166
}

The views expressed are those of the individual authors and do not necessarily reflect official positions of the Federal Reserve Bank of St. Louis, the Federal Reserve System, or the Board of Governors.

Federal Reserve Bank of St. Louis Working Papers are preliminary materials circulated to stimulate discussion and critical comment. References in publications to Federal Reserve Bank of St. Louis Working Papers (other than an acknowledgment that the writer has had access to unpublished material) should be cleared with the author or authors. 
September 5, 2012

\title{
On the Substitutability between Foreign Aid and International Credit $^{*}$
}

\author{
By \\ Subhayu Bandyopadhyay $§$, Sajal Lahiri $\ddagger$ and Javed Younas $\S \S$
}

\begin{abstract}
We examine the effect of relaxing a binding borrowing constraint for a recipient country on the amount of foreign aid it receives. We do so by developing a two-country, two-period trade-theoretic model. The relaxation of the borrowing constraint reduces the flow of foreign aid, suggesting that the donor views developing nations' access to international credit markets as a substitute for foreign aid.
\end{abstract}

Keywords: Foreign aid, borrowing constraint, fungibility, public input.

JEL Classification: F35, O10.

$\S$ Federal Reserve Bank of St. Louis, Research Division, PO Box 442, St. Louis, MO 63166-0442, U.S.A.; and Research Fellow at IZA, Bonn, Germany;

E-mail: Subhayu.Bandyopadhyay@stls.frb.org

$\ddagger$ Department of Economics, Southern Illinois University Carbondale, Carbondale, IL 62901-4515, U.S.A.; E-mail: lahiri@siu.edu

$\S \S$ Department of Economics, American University of Sharjah, PO Box 26666, Sharjah, UAE; Email: jyounas@aus.edu;

* The views expressed are those of the authors and do not necessarily represent official positions of the Federal Reserve Bank of St. Louis or of the Federal Reserve System. 


\section{Introduction}

Does a more severely credit constrained country receive a larger quantity of foreign aid? We address this question by developing a two-period, two-country (recipient and donor) trade-theoretic model where the recipient country is subject to a binding borrowing constraint. ${ }^{1,2}$ Aid is given by the donor in the first period for the provision of a public input in the recipient nation to boost production in the second period. However, foreign aid is fully fungible, and the recipient government optimally chooses to spend only a certain fraction of the aid for the public input, while diverting the rest to its citizens as lump-sum payments. Simultaneously, the altruistic donor government optimally chooses the level of foreign aid. ${ }^{3}$ This paper analyzes how a relaxation of the borrowing constraint affects the equilibrium level of foreign aid.

\section{The Model}

There are two countries, and two periods. In period 1, the recipient country (labeled $\alpha$ ) receives $T$ amount of foreign aid from the donor, for the purpose of providing a public input, the level of which is denoted by $g$. However, foreign aid is fully fungible and the recipient can allocate a proportion (1$\lambda$ ) of it as lump-sum payments to consumers. ${ }^{4}$ Thus, the recipient government uses a proportion $\lambda$ of foreign aid and also an amount $\bar{L}$ obtained by lump-sum taxation of its nationals, to pay for $g$ which increases production in period 2. Given the difficulties in most countries with lump-sum taxation, we take $\bar{L}$ to be exogenous. There are $n$ private goods produced and consumed in both nations. Consumption in the two economies is represented by the inter-temporal expenditure function of a representative consumer: $E^{\alpha}\left(p, p /(1+r), u^{\alpha}\right)$ and $E^{\beta}\left(p, p /\left(1+r^{*}\right), u^{\beta}-\theta u^{\alpha}\right)$ respectively. Also, $u^{\alpha}$ and $u^{\beta}$, and $r$ and $r^{*}$, are the respective utility levels and interest rates, while $p$ is the price vector. We assume that the donor nation's representative consumer is altruistic toward its counterpart in

\footnotetext{
${ }^{1}$ Bauer (1971) argued that it should be replaced by free or easier access to the international credit market. Stern (1974) while reviewing Bauer (1971) made a robust defense of foreign aid as an instrument for development.

${ }^{2}$ For extensive evidence suggesting that developing countries face severe credit constraints, see, among others, Galindo and Schiantarelli (2003), and Harrison and McMillan (2003). Also, see Rajan and Zingales (1998) for evidence on sector-level financial development.

${ }^{3}$ In reality, donors have many motives for giving foreign aid, and self-interest also plays a major role.

${ }^{4}$ Often, for all intents and purposes, aid is fungible (see Boone, 1996; Swaroop et al., 2000).
} 
the recipient country, and $\theta$ is the altruism parameter. Both countries are small open economies in the goods market, so $p$ is exogenously given. The period 1 revenue functions (representing value added) in the two countries are $R^{\alpha 1}(p, \bar{K})$ and $R^{\beta 1}(p)$, where $\bar{K}$ is the initial capital stock in the recipient country. ${ }^{5}$ In period 2 , the revenue functions are $R^{\alpha 2}(p, \bar{K}+I, g)$ and $R^{\beta 2}(p)$ where $I$ is investment made in period $1, R_{33}^{\alpha 2} \leq 0$, and $R_{22}^{\alpha 2}<0$. We assume that private capital and public input are complements $\left(R_{23}^{\alpha 2} \geq 0\right)$.

The inter-temporal budget constraint for the representative consumers are:

$$
\begin{aligned}
E^{\alpha}\left(p, p /(1+r), u^{\alpha}\right)+I & =R^{\alpha 1}(p, \bar{K})+\frac{R^{\alpha 2}(p, \bar{K}+I, g)}{1+r}-\bar{L}+(1-\lambda) T, \\
E^{\beta}\left(p, p /\left(1+r^{*}\right), u^{\beta}-\theta u^{\alpha}\right) & =R^{\beta 1}(p)+\frac{R^{\beta 2}(p)}{1+r^{*}}-T,
\end{aligned}
$$

where $(1-\lambda) T$ is the part of foreign aid that is returned to the representative consumer in recipient country as a lump-sum transfer.

The budget constraint for the government in the recipient country is:

$$
g=\bar{L}+\lambda T
$$

i.e., public input is financed by a fixed lump-sum taxation and a proportion of foreign aid.

The level of investment in the recipient country is determined optimally by the representative consumer. It is done by setting $\partial u^{\alpha} / \partial I=0$, taking $r$ as given. This gives:

$$
1=R_{2}^{\alpha 2} /(1+r)
$$

The left-hand side is the marginal cost of investment in the sense of consumption foregone, and the right-hand side is the present value of the marginal return to investment.

The representative consumer in the donor country is assumed to be able to borrow freely from the international capital market at an exogenous interest rate $r^{*}$. However, the representative

\footnotetext{
${ }^{5}$ Partial derivatives of the revenue and the expenditure functions with respect to the price of a good yield the supply and compensated demand functions for this good, respectively. Partial derivative with respect to argument $i$ is represented by corresponding subscript in the functional form. For properties of these functions, see Dixit and Norman (1980), among others. Also, all vectors are column vectors, and for a vector $x$, its transpose is denoted by $x^{\prime}$. Finally, endowment other than capital are omitted as they do not vary in our analysis.
} 
consumer in the recipient country is subject to a binding borrowing constraint, where he/she can borrow up to $\bar{B}$ in period 1 and repay this amount with interest in period 2. Therefore: ${ }^{6}$

$$
B^{\alpha}(r, T, \lambda) \equiv p^{\prime} E_{1}^{\alpha}+I-\left[R^{\alpha 1}-\bar{L}+(1-\lambda) T\right]=\bar{B}=\frac{R^{\alpha 2}-p^{\prime} E_{2}^{\alpha}}{1+r},
$$

where $B^{\alpha}(\cdot)$ is the demand for loans in period 1 in the recipient country.

This completes the description of the basic model. It has five equations in (1)-(5) and five endogenous variables $u^{\alpha}, u^{\beta}, g, I$ and $r$.

\section{Substitutability between Loans and Foreign Aid}

Differentiating (1)-(3) and using (4) and (5), we get:

$$
\begin{aligned}
E_{3}^{\alpha} d u^{\alpha} & =-\frac{\bar{B}}{1+r} \cdot d r+\left[\frac{\lambda R_{3}^{\alpha 2}}{1+r}+(1-\lambda)\right] d T+T\left[\frac{R_{3}^{\alpha 2}}{1+r}-1\right] d \lambda, \\
E_{3}^{\beta} d\left(u^{\beta}-\theta u^{\alpha}\right) & =-d T
\end{aligned}
$$

where $E_{3}^{i}$ is the reciprocal of the marginal utility of income in country $i(i=\alpha, \beta)$. Also, $E_{33}^{i}>0$ $(i=\alpha, \beta)$ implying diminishing marginal utility of income.

The first term on the right-hand side of (6) is the intertemporal term-of-trade effect: an increase in $r$ lowers the borrower's utility. For given levels of $r$ and $\lambda$, an increase in foreign aid raises the welfare of the recipient in two ways: (i) it increases $g$ and thus $u^{\alpha}$ through production augmentation, and this effect is proportional to $\lambda$, and (ii) it increases the lump-sum income of the recipient from the aid not allocated for the public input. On the other hand, for given $T$ and $r$, an increase in $\lambda$ raises recipient utility through an increase in the public input, and reduces the utility as lump-sum transfers are cut. Finally, an increase in aid must reduce the donor's utility, for a given level of recipient utility (see (7)).

Differentiating (4), we get:

$$
R_{22}^{\alpha 2} d I=-R_{23}^{\alpha 2} d g+d r .
$$

\footnotetext{
${ }^{6}$ For the treatment of borrowing constraints in similar way see, for example, Djajić (2010).
} 
An increase in $g$ increases $I$ because of the complementarity between the public input and private capital, and an increase in $r$ reduces $I$ by reducing the present value of the rate of return.

Differentiating (5), and using (6), (3) and (8), we find:

$$
\begin{aligned}
-\frac{\bar{B} \epsilon^{\alpha}}{1+r} \cdot d r= & d \bar{B}+\left[-c_{y}^{\alpha 1}\left\{\frac{\lambda R_{3}^{\alpha 2}}{1+r}+(1-\lambda)\right\}+\frac{\lambda R_{23}^{\alpha 2}}{R_{22}^{\alpha 2}}+(1-\lambda)\right] d T \\
& -T\left[\frac{c_{y}^{\alpha 1} R_{3}^{\alpha 2}}{1+r}-\frac{R_{23}^{\alpha 2}}{R_{22}^{\alpha 2}}+\left(1-c_{y}^{\alpha 1}\right)\right] d \lambda
\end{aligned}
$$

where $c_{y}^{\alpha 1}$ is the marginal propensity to spend on period 1 consumption, i.e.,

$$
c_{y}^{\alpha 1}=\frac{\partial\left(p_{1}^{\prime \alpha}\right)}{\partial u^{\alpha}} \cdot \frac{1}{E_{3}^{\alpha}}=\frac{p_{13}^{\prime \alpha}}{E_{3}^{\alpha}}>0,
$$

and $\epsilon^{\alpha}$ is the absolute value of the loans demand elasticity with respect to the interest rate:

$$
\epsilon^{\alpha}=-\frac{\partial B^{\alpha}}{\partial(1+r)} \cdot \frac{1+r}{\bar{B}}>0
$$

The first term on the right-hand-side of (9) is the direct effect of the relaxation of $\bar{B}$, which must reduce the interest rate $r$. Turning to the effects of an increase in $T$, we note the following regarding the three terms in the coefficient of $d T$ in (9). First, a rise in $T$ increases the utility of the recipient and thus the level of private consumption in period 1. This increases the demand for loans and hence $r$. Second, an increase in $T$ increases $g$, making investments more profitable. This increases the demand for loans and in turn $r$. Finally, as $T$ increases, lump-sum income rises for the recipient, reducing the demand for loans and the equilibrium interest rate. The effects of an increase in $\lambda$ are similar, except that an increase in $\lambda$ reduces the lump-sum income of the recipient in period 1 and this increases the demand for loans and the equilibrium interest rate.

Substituting (9) in (6), we get:

$$
\begin{aligned}
E_{3}^{\alpha} d u^{\alpha} & =\frac{1}{\epsilon^{\alpha}} \cdot d \bar{B}+T\left[\left\{\frac{R_{3}^{\alpha 2}}{1+r}-1\right\}\left\{\frac{\epsilon^{\alpha}-c_{y}^{\alpha 1}}{\epsilon^{\alpha}}\right\}+\frac{R_{23}^{\alpha 2}}{\epsilon^{\alpha} R_{22}^{\alpha 2}}-\frac{1}{\epsilon^{\alpha}}\right] d \lambda \\
& +\left[\left\{\frac{\lambda R_{3}^{\alpha 2}}{1+r}+(1-\lambda)\right\}\left\{\frac{\epsilon^{\alpha}-c_{y}^{\alpha 1}}{\epsilon^{\alpha}}\right\}+\frac{\lambda R_{23}^{\alpha 2}}{\epsilon^{\alpha} R_{22}^{\alpha 2}}+\frac{(1-\lambda)}{\epsilon^{\alpha}}\right] d T
\end{aligned}
$$


A relaxation of the borrowing constraint increases welfare by reducing the interest rate. The effects of $T$ and $\lambda$ on $u^{\alpha}$ now have, in addition to the ones discussed after (6), the effects via induced changes in the interest rate.

As for the donor country, we substitute (10) in (7) to get:

$$
\begin{gathered}
E_{3}^{\beta} d u^{\beta}=\frac{\theta E_{3}^{\beta}}{E_{3}^{\alpha} \epsilon^{\alpha}} \cdot d \bar{B}+\frac{T \theta E_{3}^{\beta}}{E_{3}^{\alpha}}\left[\left\{\frac{R_{3}^{\alpha 2}}{1+r}-1\right\}\left\{\frac{\epsilon^{\alpha}-c_{y}^{\alpha 1}}{\epsilon^{\alpha}}\right\}+\frac{R_{23}^{\alpha 2}}{\epsilon^{\alpha} R_{22}^{\alpha 2}}+\frac{1}{\epsilon^{\alpha}}\right] d \lambda \\
+\quad\left[-1+\frac{\theta E_{3}^{\beta}}{E_{3}^{\alpha}}\left(\left\{\frac{\lambda R_{3}^{\alpha 2}}{1+r}+(1-\lambda)\right\}\left\{\frac{\epsilon^{\alpha}-c_{y}^{\alpha 1}}{\epsilon^{\alpha}}\right\}+\frac{\lambda R_{23}^{\alpha 2}}{\epsilon^{\alpha} R_{22}^{\alpha 2}}+\frac{(1-\lambda)}{\epsilon^{\alpha}}\right)\right] d T .
\end{gathered}
$$

Most of the effects in (11) appear via changes in the utility of the recipient and those have been explained before. The only extra effect is the direct negative effect of $T$ on donor welfare (see (7)). This extra effect is the first term in the coefficient of $d T$ above.

We now consider a simultaneous-move game where the recipient chooses $\lambda$ and the donor $T$. After setting $\partial u^{\alpha} / \partial \lambda=0$ and $\partial u^{\beta} / \partial T=0$, we get the first order conditions as:

$$
\left[\epsilon^{\alpha}-c_{y}^{\alpha 1}-\frac{\epsilon_{23}^{\alpha}}{\epsilon_{22}^{\alpha}}\right] R_{3}^{\alpha 2}-(1+r)\left(1+\epsilon^{\alpha}-c_{y}^{\alpha 1}\right)=0
$$

$$
\begin{aligned}
& \text { where } \epsilon_{23}^{\alpha}=\frac{\partial R_{3}^{\alpha 2}}{\partial(\bar{K}+I)} \cdot \frac{\bar{K}+I}{R_{3}^{\alpha 2}}=R_{23}^{\alpha 2} \cdot \frac{\bar{K}+I}{R_{3}^{\alpha 2}}>0 \\
& \epsilon_{22}^{\alpha}=-\frac{\partial R_{2}^{\alpha 2}}{\partial(\bar{K}+I)} \cdot \frac{\bar{K}+I}{R_{2}^{\alpha 2}}=-R_{22}^{\alpha 2} \cdot \frac{\bar{K}+I}{R_{2}^{\alpha 2}}=-R_{22}^{\alpha 2} \cdot \frac{\bar{K}+I}{1+r}>0 \\
& -1+\frac{\theta E_{3}^{\beta}}{E_{3}^{\alpha}}\left(\left\{\frac{\lambda R_{3}^{\alpha 2}}{1+r}+(1-\lambda)\right\}\left\{\frac{\epsilon^{\alpha}-c_{y}^{\alpha 1}}{\epsilon^{\alpha}}\right\}-\frac{\lambda \epsilon_{23}^{\alpha} R_{3}^{\alpha 2}}{\epsilon^{\alpha} \epsilon_{22}^{\alpha}(1+r)}+\frac{(1-\lambda)}{\epsilon^{\alpha}}\right)=0 .
\end{aligned}
$$

There are two groups of effects from a rise in $\lambda$ on the welfare of the recipient. The first is via an increase in $g$ and these effects are given by the first term in (12). The second group of effects comes via a reduction in the lump-sump income out of foreign aid (induced by an increase in $\lambda$ ). These are given by the second term in (12). For the donor, the first effect is a negative direct one 
as aid is given by taxing the representative consumer, and the second effects come via the altruism factor.

Equations (12) and (13) simultaneously determine the equilibrium levels of $T$ and $\lambda$ in terms of $\bar{B}$ and other exogenous variables.

For tractability, we assume that the total effect (after considering effects via changes in $T$ and $\lambda$ as well as the direct effect) of relaxing the borrowing constraint on the rate of interest is negative (i.e., $d r / d \bar{B}<0)$.

After substituting (12) into (13), the latter simplifies to:

$$
\theta E_{3}^{\beta}\left(1+\epsilon^{\alpha}-c_{y}^{\alpha 1}\right)=E_{3}^{\alpha} \epsilon^{\alpha}
$$

and (10) simplifies to

$$
E_{3}^{\alpha} d u^{\alpha}=\frac{1}{\epsilon^{\alpha}} \cdot d \bar{B}+\left[1+\frac{1-c_{y}^{\alpha 1}}{\epsilon^{\alpha}}\right] d T .
$$

Differentiating (14) and using (7) and (15), we get

$$
\begin{gathered}
-A d T=B d \bar{B} \\
\text { where } A=\frac{\theta E_{33}^{\beta}\left(1+\epsilon^{\alpha}-c_{y}^{\alpha 1}\right)}{E_{3}^{\beta}}+\frac{E_{33}^{\alpha}\left(1+\epsilon^{\alpha}-c_{y}^{\alpha 1}\right)}{E_{3}^{\alpha}}>0, \\
\qquad B=\frac{E_{33}^{\alpha}}{E_{3}^{\alpha}}-\frac{\left(1-c_{y}^{\alpha 1}\right) \epsilon^{\alpha} E_{3}^{\alpha}}{1+r} \cdot \frac{d r}{d \bar{B}}>0 .
\end{gathered}
$$

From (16), our main result follows:

Proposition 1 A relaxation of the borrowing constraint for a foreign aid recipient country reduces the amount of aid it receives.

Thus, foreign loan and foreign aid are substitutes. An increase in $\bar{B}$ increases real income in the recipient country, which reduces the marginal utility of income in that country. In turn, this lowers 
the marginal benefit of giving foreign aid for the donor nation. A reduction in the interest rate induced by the relaxation of the borrowing constraint also reduces the marginal utility of income in the recipient country by increasing the present value of the price of the good in the second period. Thus, both effects work in the same direction to reduce foreign aid.

\section{Conclusion}

Using a trade-theoretic model with a credit constarined recipient, we find that a relaxation of the borrowing constraint unambiguously reduces the amount of foeign aid that is given by an altruistic donor. This suggests that an altrustic donor views access to international credit markets for poorer nations as a substitute to its foreign aid efforts.

\section{References}

[1] Bauer, P.T. (1971). Dissent on Development, London: Widenfeld and Nicolson.

[2] Boone, P. (1996). "Politics and the effectiveness of foreign aid," European Economic Review, 40, 289-329.

[3] Dixit, A., and Norman, V. (1980). Theory of International Trade, Cambridge: Cambridge University Press.

[4] Djajić, S. (2010). "Investment Opportunities in the Source Country and Temporary Migration," Canadian Journal of Economics, 43, 663-682.

[5] Galindo, A. and Schiantarelli, F. (editors) (2003). Credit constraints and investment in Latin America, Inter-American Development Bank, Washington, DC.

[6] Harrison, A. and McMillan, M. (2003). Does direct foreign investment affect domestic credit constraints?" Journal of International Economics, 61, 73-100.

[7] Rajan, R. and Zingales, L. (1998). "Financial dependence and growth," American Economic Review, 88, 559-586.

[8] Stern, N.H. (1974). "Professor Bauer on development: a review article," Journal of Development Economics, 1, 191-211.

[9] Swaroop, V., S. Jha, A.S. Rajkumar, and A. Sunil. (2000). "Fiscal Effects of Foreign Aid in a Federal System of Governance: The Case of India". Journal of Public Economics, 22, 307-330. 